\title{
An Octacalcium Phosphate Forming Cement
}

\section{Markovic and L. C. Chow}

American Dental Association

Foundation,

Paffenbarger Research Center, National Institute of Standards and Technology,

Gaithersburg, MD 20899, U.S.A.

milenko.markovic@nist.gov larry.chow@nist.gov

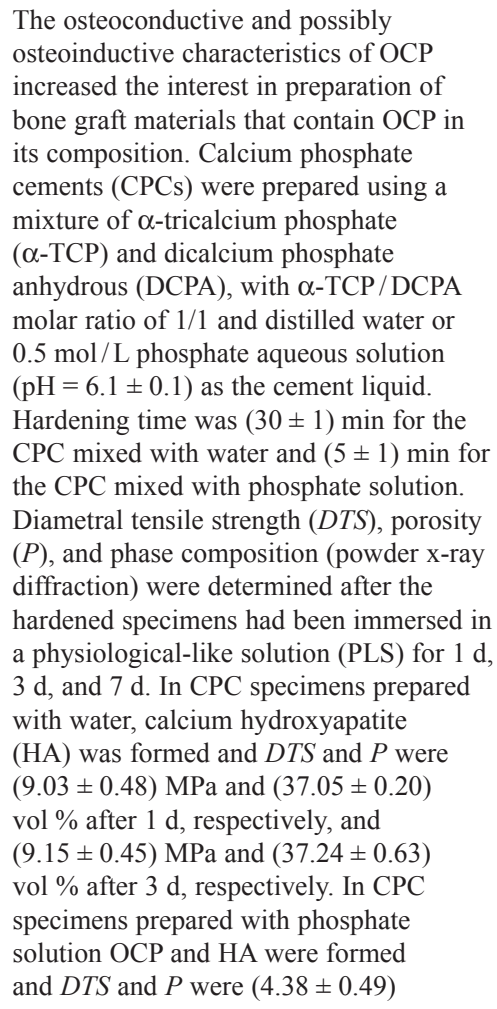

The osteoconductive and possibly osteoinductive characteristics of OCP increased the interest in preparation of bone graft materials that contain OCP in its composition. Calcium phosphate cements (CPCs) were prepared using a mixture of $\alpha$-tricalcium phosphate $(\alpha-\mathrm{TCP})$ and dicalcium phosphate anhydrous (DCPA), with $\alpha$-TCP / DCPA molar ratio of $1 / 1$ and distilled water or $0.5 \mathrm{~mol} / \mathrm{L}$ phosphate aqueous solution $(\mathrm{pH}=6.1 \pm 0.1)$ as the cement liquid. Hardening time was $(30 \pm 1)$ min for the $\mathrm{CPC}$ mixed with water and $(5 \pm 1)$ min for the CPC mixed with phosphate solution. Diametral tensile strength (DTS), porosity $(P)$, and phase composition (powder $\mathrm{x}$-ray diffraction) were determined after the hardened specimens had been immersed in a physiological-like solution (PLS) for $1 \mathrm{~d}$, $3 \mathrm{~d}$, and $7 \mathrm{~d}$. In CPC specimens prepared with water, calcium hydroxyapatite (HA) was formed and DTS and $P$ were $(9.03 \pm 0.48) \mathrm{MPa}$ and $(37.05 \pm 0.20)$ vol \% after $1 \mathrm{~d}$, respectively, and $(9.15 \pm 0.45) \mathrm{MPa}$ and $(37.24 \pm 0.63)$ vol \% after $3 \mathrm{~d}$, respectively. In CPC specimens prepared with phosphate solution OCP and HA were formed and DTS and $P$ were $(4.38 \pm 0.49)$

\begin{abstract}
$\mathrm{MPa}$ and $(41.44 \pm 1.25)$ vol $\%$ after $1 \mathrm{~d}$, respectively, $(4.38 \pm 0.29) \mathrm{MPa}$ and $(42.52 \pm 2.15)$ vol $\%$ after $3 \mathrm{~d}$, respectively, and $(4.30 \pm 0.60) \mathrm{MPa}$ and $(41.38 \pm 1.65)$ vol $\%$ after $7 \mathrm{~d}$, respectively. For each group DTS and $P$ did not change with PLS immersion time. $D T S$ was significantly higher and $P$ was significantly lower for CPCs prepared with water. HA formation slightly increased with immersion time from 40 mass $\%$ after $1 \mathrm{~d}$ to 50 mass \% after $3 \mathrm{~d}$ in CPCs prepared with water. OCP + HA formation increased with immersion time from 30 mass $\%$ after $1 \mathrm{~d}$ to 35 mass $\%$ after $3 \mathrm{~d}$ and to 45 mass \% after $7 \mathrm{~d}$ in CPCs prepared with $0.5 \mathrm{~mol} / \mathrm{L}$ phosphate solution.
\end{abstract}

Key words: calcium hydroxyapatite; calcium phosphate cement; cement liquids; diametral tensile strength; hardening time; octacalcium phosphate.

Accepted: April 16, 2010

Available online: http://www.nist.gov/jres

\section{Introduction}

Octacalcium phosphate $\left(\mathrm{Ca}_{8} \mathrm{H}_{2}\left(\mathrm{PO}_{4}\right)_{6} \cdot 5 \mathrm{H}_{2} \mathrm{O}\right.$; OCP $)$ has been proposed to be a precursor in the formation of apatitic calcium phosphate minerals in bones and teeth [1]. OCP is more soluble and less stable at physiological conditions than calcium hydroxyapatite $\left(\mathrm{Ca}_{10}\left(\mathrm{PO}_{4}\right)_{6}(\mathrm{OH})_{2}\right.$; $\left.\mathrm{HA}\right)$ [1]. OCP has a layer-type structure composed of alternating hydrated and apatitic layers [2]. The hydrolysis of OCP to HA is thermodynamically favored and it proceeds spontaneously and irreversibly $[3,4]$. Recent studies demonstrated that synthetic OCP could stimulate osteoblastic cell differentiation in vitro [5-8]. In vivo studies showed that synthetic OCP was converted to apatitic material in muscle [9] and subcutaneous [10] tissues and at different bony sites $[5,10,11]$. It was also shown that resorption of OCP was followed by replacement of newly formed bone [12-15]. In addition, OCP coating on metallic implants was reported to promote osteoconductivity [16], osteoblastic cell proliferation [17] and in some cases ectopic osteoinductivity $[14,18]$. The conversion of OCP to HA itself was suggested to be one of the factors that stimulate osteoblastic cell differentiation $[5,8]$.

The osteoconductive and possibly osteoinductive characteristics of OCP increased the interest in preparation of bone graft materials that contain OCP in its 
composition. Calcium phosphate cements (CPCs) that are mixtures of two (or more) powdered calcium and/or phosphate containing materials that harden with addition of an aqueous solution are good candidates for formation of OCP. Monma et al., [19] reported that they obtained OCP by reaction of $\alpha$-tricalcium phosphate $\left(\alpha-\mathrm{Ca}_{3}\left(\mathrm{PO}_{4}\right)_{2} ; \alpha-\mathrm{TCP}\right)$ and dicalcium phosphate dihydrate $\left(\mathrm{CaHPO}_{4} \cdot 2 \mathrm{H}_{2} \mathrm{O} ; \mathrm{DCPD}\right)$ in water. Bermudez et al., [20] reported that OCP was formed in a CPC composed of $\alpha$-TCP and dicalcium phosphate anhydrous $\left(\mathrm{CaHPO}_{4} ; \mathrm{DCPA}\right)$ as the solid components and water as the cement liquid, but the hardening time of this CPC was relatively slow $(30 \mathrm{~min})$. Sena et al., [21] also suggested formation of OCP in a CPC, consisting of a three component powder mixture $\left(\alpha-\mathrm{TCP}+\mathrm{CaCO}_{3}+\right.$ $\left.\mathrm{Ca}\left(\mathrm{H}_{2} \mathrm{PO}_{4}\right)_{2}\right)$ and a phosphate aqueous solution $(\mathrm{pH}=7.4)$, that was used as a pulp filler.

The objective of this study was to prepare fast selfhardening calcium phosphate cement in which OCP is formed. Based on our experience in CPCs with different powder and cement liquid compositions [22-25] and hydrolysis of calcium phosphate compounds $[26,27]$ we hypothesized that the CPC mixture of powdered $\alpha$-TCP and DCPA, both having appropriate particle sizes could produce formation of OCP in reaction with an aqueous solution.

\section{Materials and Methods ${ }^{1}$}

The $\alpha$-tricalcium phosphate $(\alpha$-TCP) with $\mathrm{Ca} / \mathrm{P}$ molar ratio of 1.50 was prepared by heating a mixture consisting of equimolar amounts of reagent grade calcium carbonate and dicalcium phosphate anhydrous (DCPA) (both from J. T. Baker Chemical Co., Phillipsburg, NJ, U.S.A.) at $1100{ }^{\circ} \mathrm{C}$ for $8 \mathrm{~h}$ in a furnace (Lindberg, Model 51333, Watertown, WI, U.S.A.) and quenched in air. The $\alpha$-TCP was ground for 6 min in the planetary ball mill (PM4, Retsch Inc., Newtown, PA, U.S.A.) obtaining 90 mass $\%$ of $\alpha$-TCP particles between $13 \mu \mathrm{m}$ and $20 \mu \mathrm{m}$ in diameter with median particle size of $15.8 \mu \mathrm{m} \pm 1.2 \mu \mathrm{m}$ in diameter (mean \pm standard deviation; $\mathrm{n}=3$ ) (SA-CPR, Shimadzu, Kyoto, Japan). Additional portion of DCPA was ground in ethanol in the planetary ball mill for $24 \mathrm{~h}$. The

\footnotetext{
${ }^{1}$ Certain commercial materials and equipment are identified in this paper to specify the experimental procedure. In no instance does such identification imply recommendation or endorsement by the National Institute of Standards and Technology, the National Institutes of Health, or the ADA Foundation or that the material or equipment identified is necessarily the best available for the purpose.
}

ground DCPA particles had median diameter of $1.4 \mu \mathrm{m} \pm 0.2 \mu \mathrm{m}(\mathrm{n}=3)$ and 90 mass $\%$ of particles had a size distribution between $1.1 \mu \mathrm{m}$ and $1.6 \mu \mathrm{m}$ in diameter.

The $\mathrm{CPC}$ powdered mixture with a $\mathrm{Ca} / \mathrm{P}$ molar ratio of 1.33 was prepared by mixing 69.5 mass $\%$ of $\alpha$-TCP and 30.5 mass $\%$ of DCPA (molar ratio of $\alpha$-TCP/DCPA is $1: 1)$. Distilled water or a $0.5 \mathrm{~mol} / \mathrm{L}$ phosphate solution with $\mathrm{pH}=6.1$ were used as cement liquids. The phosphate solution was prepared by mixing equal volumes of $0.5 \mathrm{~mol} / \mathrm{L} \mathrm{NaH}_{2} \mathrm{PO}_{4}$ and $0.5 \mathrm{~mol} / \mathrm{L} \mathrm{Na}_{2} \mathrm{HPO}_{4}$ solutions. CPC specimens were prepared by placing the powdered mixture on a glass mixing slab, dispensing the liquid on the powder using a micropipette, and mixing the paste using a stainless steel spatula for $30 \mathrm{~s}$. The powder to liquid ratio $(\mathrm{P} / \mathrm{L})$ that produced paste with optimal consistency was $3 \mathrm{~g} / \mathrm{mL}$.

For hardening time (HT) determinations, $400 \mathrm{mg}$ of $\mathrm{CPC}$ powder was mixed with $133 \mu \mathrm{L}$ of cement liquid. The paste was packed into a stainless steel mold with a cylindrical hole of $6 \mathrm{~mm}$ in diameter and $3 \mathrm{~mm}$ in height. A pressure of $0.7 \mathrm{MPa}$ was applied for $10 \mathrm{~s}$, after which both the top and bottom surfaces of the mold were covered with glass plates and kept in a $100 \%$ humidity box at $37^{\circ} \mathrm{C}$. Because cement hardening occurred very fast when the phosphate solution was the cement liquid, it was desirable to complete the sample preparation procedure within the shortest possible time. In the present study, the sample preparation time starting from delivery of the liquid onto the cement powder to completion of packing the cement paste into the mold was less than $60 \mathrm{~s}$. The $H T$ was determined by a large Gilmore needle.

For diametral tensile strength (DTS) determination $154.3 \mathrm{mg}$ of the CPC powder was mixed with $51.4 \mu \mathrm{L}$ of cement liquid. The paste was mixed for $30 \mathrm{~s}$ and placed into the cylindrical stainless steel mold as previously described [28]. Briefly, the mold body consists of a cylinder $(25.4 \mathrm{~mm}$ in diameter and $33.0 \mathrm{~mm}$ in height) with a $6 \mathrm{~mm}$ diameter hole drilled through the center. Two stainless steel plungers of the same dimensions $(6 \mathrm{~mm}$ in diameter and $3.20 \mathrm{~mm}$ in height) were used. The bottom plunger was dropped into the mold cavity and then the cement paste was placed into the cavity and lightly packed down with a rod. The top plunger was then inserted into the cavity. The mold assembly, with an approximately $6 \mathrm{~mm}$ length of each plunger extended out of the mold body, was placed in the constant pressure-loading device with the pressure of $0.7 \mathrm{MPa}$ applied for $4 \mathrm{~h}$ [28] and kept in a $100 \%$ humidity box at $37^{\circ} \mathrm{C}$. After $4 \mathrm{~h}$ the hardened specimen was removed from the mold and placed in approxi- 
mately $15 \mathrm{~mL}$ of a physiological-like solution (PLS) [29] at $37^{\circ} \mathrm{C}$. The PLS has a composition similar to that of serum in terms of calcium, phosphate, $\mathrm{pH}$, and electrolyte content: $c\left(\mathrm{CaCl}_{2}\right)=1.15 \mathrm{mmol} / \mathrm{L}$, $c\left(\mathrm{KH}_{2} \mathrm{PO}_{4}\right)=1.20 \mathrm{mmol} / \mathrm{L}, c(\mathrm{NaCl})=133 \mathrm{mmol} / \mathrm{L}$, $c(\mathrm{HEPES})=50 \mathrm{mmol} / \mathrm{L}$ with $\mathrm{pH}$ of 7.4 adjusted by addition of $\mathrm{KOH}$. The PLS was replaced with fresh PLS every day. The time periods between sample preparation and DTS measurements were $1 \mathrm{~d}, 3 \mathrm{~d}$ and $7 \mathrm{~d}$. Before the DTS measurement, the diameter and height of each cylindrical specimen were measured with a micrometer. DTS was measured using a Universal Testing Machine (United Calibration Corp., Huntington Beach, CA, U.S.A.) at a loading rate of $10 \mathrm{~mm} / \mathrm{min}$.

For density $(d)$ determinations, additional DTS specimens were dried for $24 \mathrm{~h}$ at $37^{\circ} \mathrm{C}$. Diameter $(D)$, height $(H)$ and mass $(m)$ of dried pellet were measured and density $(d)$ was determined using the equation $d=4 \mathrm{~m} /\left(D^{2} \pi H\right)$. Porosity $(P)$, expressed as volume percentage of empty space in the pellet, was calculated from the determined density $(d)$ and theoretical density $d_{\mathrm{t}}=3.14 \mathrm{~g} / \mathrm{cm}^{3}$ of HA [30] using equation $P=100 \times\left(1-d / d_{\mathrm{t}}\right)$.

The phase composition and morphology of solid phases were determined using powder x-ray diffraction (XRD) (Rigaku 400, Rigaku, Japan) and scanning electron microscopy (SEM) (JEOL SEM 5000, JEOL, Japan), respectively. The amount of non-reacted (residual) $\alpha$-TCP and DCPA was estimated from reduced intensities of $\alpha$-TCP and DCPA diffraction lines in CPC samples compared to the initial intensities in $\alpha$-TCP and DCPA powdered mixture.

A commercially obtained statistical analysis program, Kwikstat (TexaSoft, Cedar Hill, TX, U.S.A.), was used to perform ANOVA (analysis of variance). In this study, the standard deviation was considered as the standard uncertainty for each measured variable.

\section{Results}

The hardening time of the CPC paste with distilled water as a cement liquid was $30 \min \pm 2 \min (n=6)$. The DTS specimens had diameter in the range from $6.00 \mathrm{~mm}$ to $6.03 \mathrm{~mm}$, height in the range from $2.67 \mathrm{~mm}$ to $2.83 \mathrm{~mm}$, and mass in the range from $141.3 \mathrm{mg}$ to $150.2 \mathrm{mg}$. The DTS, density and porosity for specimens kept in PLS and determined $1 \mathrm{~d}$ or $3 \mathrm{~d}$ after preparation are listed in Table 1.

There were no significant $(p>0.05)$ differences between the values determined at two different times for any of the three measured properties.

In Fig. 1 the $x$-ray diffraction (XRD) patterns of the initial powdered mixture of $\alpha$-TCP and DCPA (Fig. 1a), and of CPC specimens prepared with distilled water and incubated in PLS for $1 \mathrm{~d}$ (Fig. 1b) and $3 \mathrm{~d}$ (Fig. 1c) are shown.

The presence of the diffraction lines at $2 \theta$ of $10.8^{\circ}$, $26.3^{\circ}, 31.8^{\circ}, 32.2^{\circ}$, and $32.9^{\circ}$ indicated formation of apatitic precipitate (HA) after $1 \mathrm{~d}$ and $3 \mathrm{~d}$ (Figs. $1 \mathrm{~b}$ and 1c) The non reacted $\alpha$-TCP and DCPA were also present (Figs. $1 b$ and 1c). From the intensities of the strongest $\alpha$-TCP and DCPA diffraction lines in the initial powdered mixture and in the CPC samples after $1 \mathrm{~d}$ and $3 \mathrm{~d}$ the estimated contents of non-reacted $\alpha$-TCP and DCPA after $1 \mathrm{~d}$ and $3 \mathrm{~d}$ were of about 60 mass \% and 50 mass $\%$, respectively. The estimated amount of HA increased from about 40 mass $\%$ to about 50 mass $\%$. The absence of the (100) diffraction line at $2 \theta=4.67^{\circ}$ that is typical for OCP indicated that OCP was not formed in these specimens.

The scanning electron micrograph (Fig. 2) of the sample after $3 \mathrm{~d}$ showed that formed HA crystals had plate like morphology with the sizes of $1 \mu \mathrm{m}$ to $3 \mu \mathrm{m}$.

Table 1. Diametral Tensile Strength $(D T S)$, density $(d)$ and porosity $(P)$ for CPC samples mixed with distilled water at powder to liquid ratio of $3 \mathrm{~g} / \mathrm{mL}$ at different reaction times ( $\mathrm{n}=6$ for each group)

\begin{tabular}{cccc}
\hline \hline Reaction Time & DTS $(\mathrm{MPa})$ & $d\left(\mathrm{~g} / \mathrm{cm}^{3}\right)$ & $P(\%)$ \\
\hline $1 \mathrm{~d}$ & $9.03 \pm 0.48$ & $1.89 \pm 0.01$ & $37.05 \pm 0.20$ \\
$3 \mathrm{~d}$ & $9.15 \pm 0.45$ & $1.88 \pm 0.02$ & $37.24 \pm 0.63$ \\
\hline
\end{tabular}




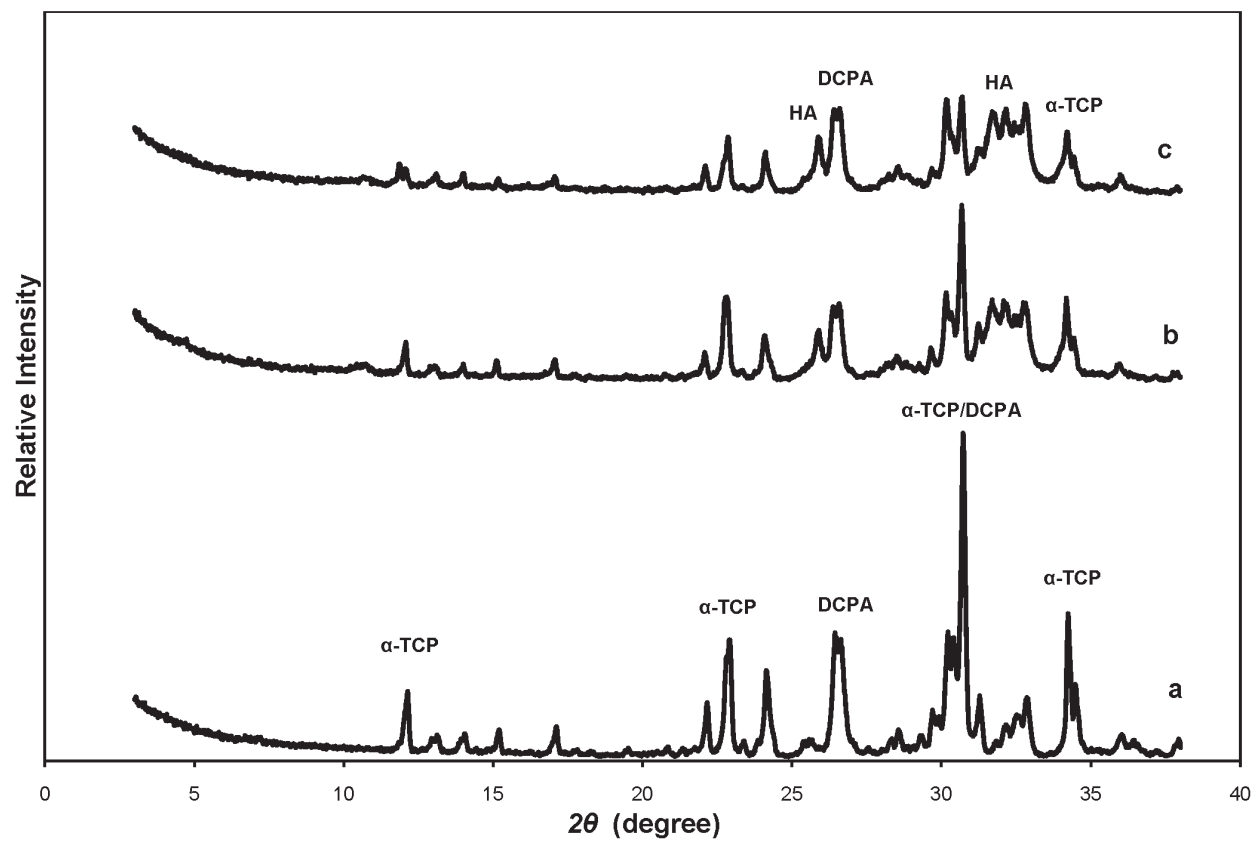

Fig. 1. Powder $x$-ray diffraction (XRD) patterns of (a) initial mixture of calcium phosphate cement (CPC) composed of $\alpha$-TCP and DCPA powders, (b) CPC product prepared with water as cement liquid and incubated in physiological-like solution (PLS) for $1 \mathrm{~d}$, and (c) CPC product prepared with water as cement liquid and incubated in PLS for $3 \mathrm{~d}$. Diffraction lines characteristic for $\alpha$-TCP, DCPA and HA are designated.

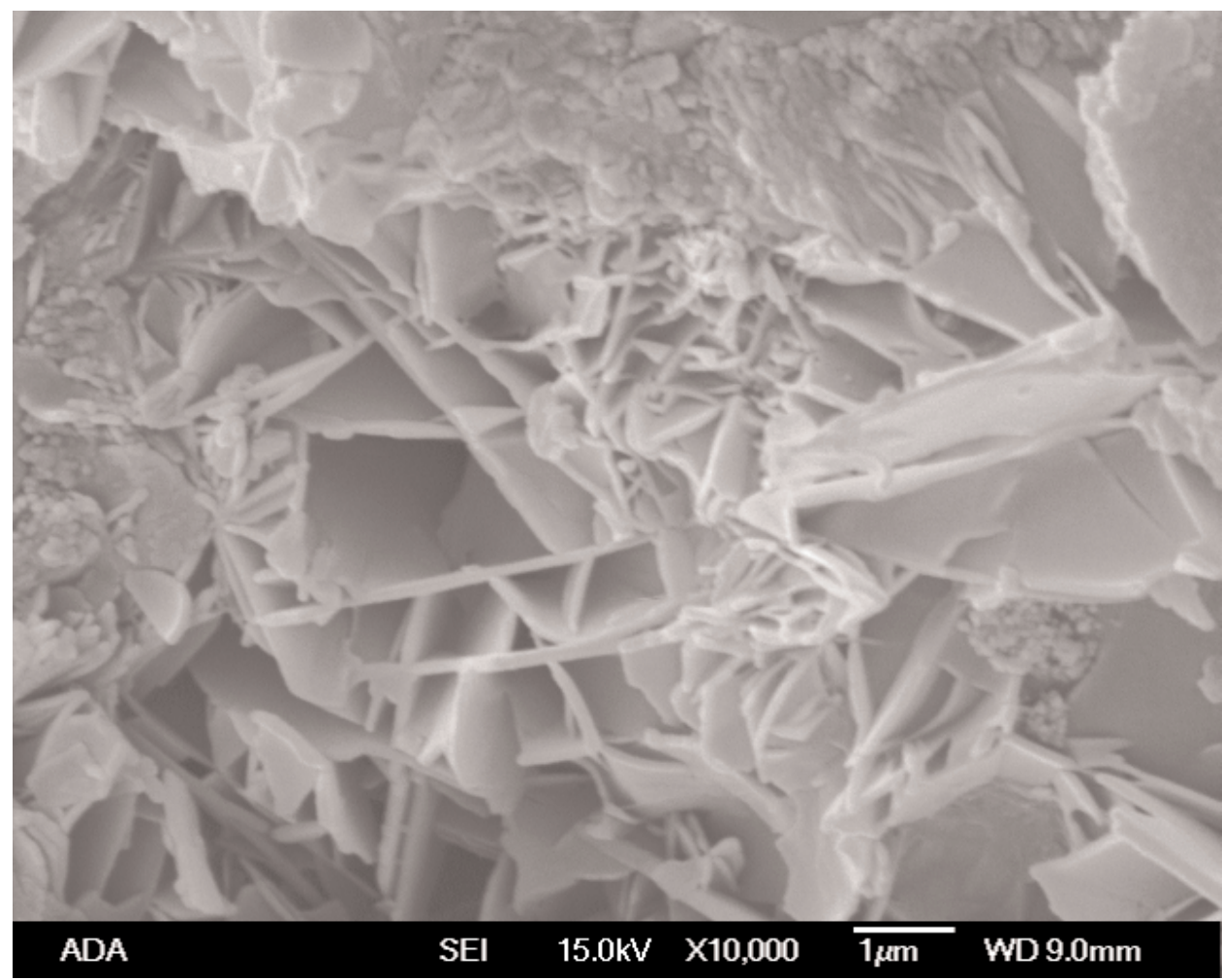

Fig. 2. Scanning electron micrograph of reacted calcium phosphate cement product prepared with water as cement liquid and incubated in physiological-like solution for $1 \mathrm{~d}$. 
The hardening time of CPC paste using the $0.5 \mathrm{~mol} / \mathrm{L}$ phosphate solution $(\mathrm{pH} 6.1)$ as the cement liquid was $5.0 \min \pm 0.5 \min (\mathrm{n}=6)$. The DTS specimens had diameter in the range from $6.00 \mathrm{~mm}$ to $6.02 \mathrm{~mm}$, height in the range from $2.92 \mathrm{~mm}$ to $3.34 \mathrm{~mm}$, and mass in the range from $151.7 \mathrm{~g}$ to $157.0 \mathrm{~g}$. The DTS, density and porosity for specimens incubated in PLS and determined $1 \mathrm{~d}, 3 \mathrm{~d}$ or $7 \mathrm{~d}$ after preparation are listed in Table 2 . There were no significant $(p>0.05)$ differences among the values measured at the three time points for $D T S, d$ or $P$.

The XRD of powdered CPC specimens after $1 \mathrm{~d}(4 \mathrm{~h}$ in water vapor and $20 \mathrm{~h}$ in PLS) showed formation of OCP (or OCP-like precipitate with combined OCP and HA layers) and the presence of residual $\alpha$-TCP and DCPA particles (Fig. 3a). The indication for OCP formation is the presence of the (100) diffraction line at $2 \theta=4.67^{\circ}$ in the XRD pattern. The intensity of this line slightly increased with time for specimens kept in PLS for $1 \mathrm{~d}$ (Fig. 3a), $3 \mathrm{~d}$ (Fig. 3b) and $7 \mathrm{~d}$ (Fig. 3c) indicating slow reaction of $\alpha$-TCP and DCPA that formed OCP precipitate in the time period from $1 \mathrm{~d}$ to $7 \mathrm{~d}$. The estimated amounts of non-reacted $\alpha$-TCP and DCPA decreased from about 70 mass $\%$ after $1 \mathrm{~d}$ to about 55 mass \% after $7 \mathrm{~d}$. The estimated amount of OCP (or OCP + HA) amount increased from about 30 mass \% after $1 \mathrm{~d}$ to about 45 mass $\%$ after $7 \mathrm{~d}$.

The scanning electron micrograph of the sample after $1 \mathrm{~d}$ (Fig. 4) showed that formed OCP crystals had plate like morphology with the particle sizes of about $0.2 \mu \mathrm{m}$ to $2 \mu \mathrm{m}$.

Table 2. Diametral Tensile Strength $(D T S)$, density $(d)$ and porosity $(P)$ for CPC samples mixed with $0.5 \mathrm{~mol} / \mathrm{L}$ Phosphate Solution $(\mathrm{pH}=6.1)$ at powder to liquid ratio of $3 \mathrm{~g} / \mathrm{mL}$ for different reaction times ( $\mathrm{n}=6$ for each group)

\begin{tabular}{crrr}
\hline \hline Reaction Time & DTS $(\mathrm{MPa})$ & $d\left(\mathrm{~g} / \mathrm{cm}^{3}\right)$ & $P(\%)$ \\
\hline $1 \mathrm{~d}$ & $4.38 \pm 0.49$ & $1.76 \pm 0.04$ & $41.44 \pm 1.25$ \\
$3 \mathrm{~d}$ & $4.38 \pm 0.29$ & $1.72 \pm 0.06$ & $42.52 \pm 2.15$ \\
$7 \mathrm{~d}$ & $4.30 \pm 0.60$ & $1.76 \pm 0.06$ & $41.38 \pm 1.65$ \\
\hline
\end{tabular}

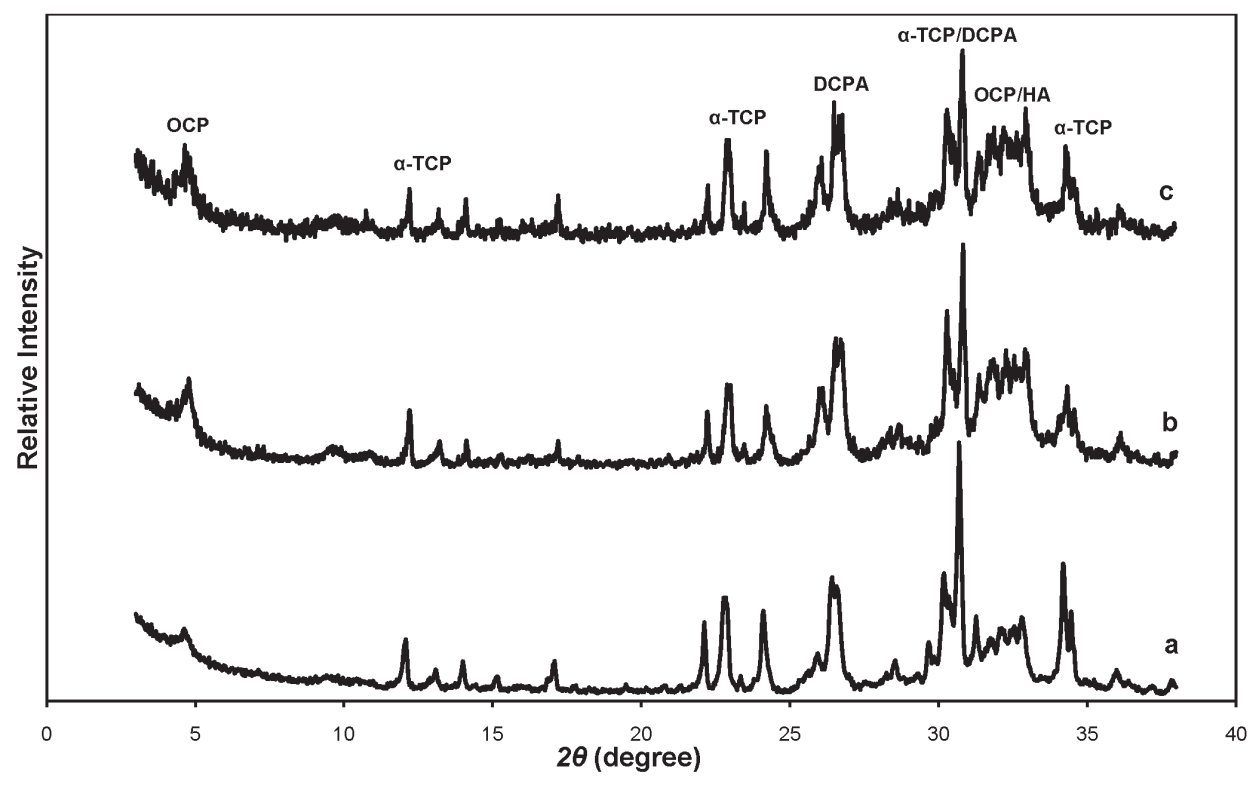

Fig. 3. Powder x-ray diffraction (XRD) patterns of calcium phosphate cement products prepared with $0.5 \mathrm{~mol} / \mathrm{L}$ phosphate solution $(\mathrm{pH}=6.1)$ as cement liquid and incubated in physiological-like solution for (a) $1 \mathrm{~d}$ (b) $3 \mathrm{~d}$ (c) $7 \mathrm{~d}$. Diffraction lines characteristic for $\alpha$-TCP, DCPA, OCP and OCP/HA are designated. 


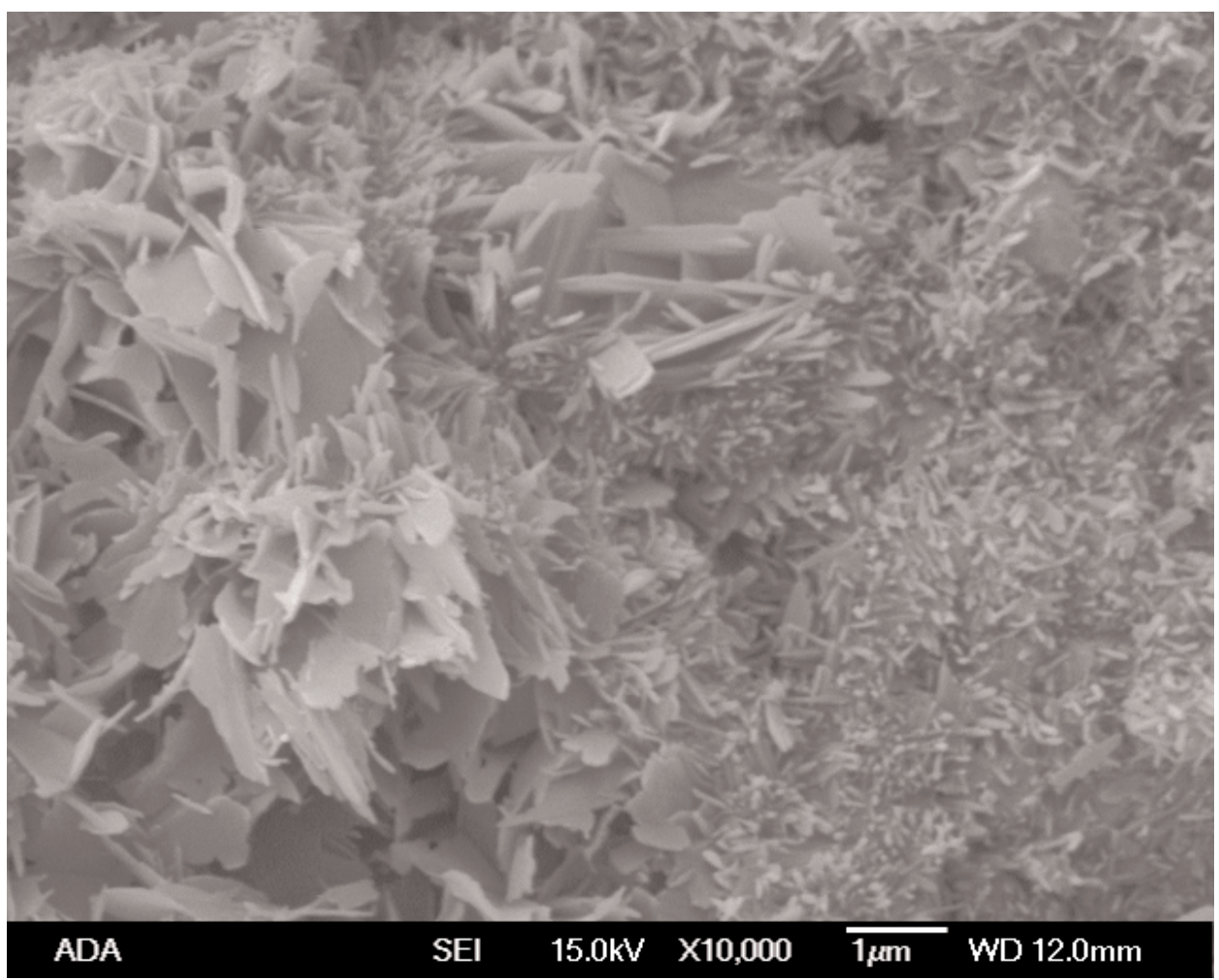

Fig. 4. Scanning electron micrograph of calcium phosphate cement product prepared with $0.5 \mathrm{~mol} / \mathrm{L}$ phosphate solution $(\mathrm{pH}=6.1)$ as cement liquid and incubated in physiological like solution for $1 \mathrm{~d}$.

The CPC samples prepared using the phosphate solution as the cement liquid had significantly $(\mathrm{p}<0.05)$ shorter $H T$, lower DTS, smaller density and larger porosity than CPCs samples prepared by using water as the cement liquid.

\section{Discussion}

Previous studies have shown that phosphate solutions significantly shorten the hardening time of several HA-forming CPCs composed of widely different initial ingredients $[24,31,32]$. The faster setting was explained by the more rapid formation of HA crystals under higher phosphate concentration in the cement liquid $[22,24]$. The present study showed, for the first time, that phosphate solution also accelerated the setting of CPCs that form OCP as a product. Since the OCP formation is likely to be responsible for the cement hardening, this finding suggests that the formation of OCP may also be accelerated by higher phosphate concentrations. The much longer hardening time of $30 \mathrm{~min}$ found for the same CPC powdered mixture when distilled water was used as the cement liquid is also in agreement with previous findings for TTCP (tetracalcium phosphate) + DCPA cements that form $\mathrm{HA}$ as the product $[22,24,31,32]$. The longer setting time of about $30 \mathrm{~min}$ was also reported by Bermudez et al., [20] who have used distilled water as the liquid and the $\alpha$-TCP + DCPA powder mixture. Interestingly, as described below, OCP but not HA was found to be the major cement product.

Some of the properties of the CPCs prepared with distilled water as the cement liquid determined in the present study can be compared with the findings of Bermudez et al., [20] in which a cement of the same starting solid components but with different particle sizes and slightly higher $\mathrm{P} / \mathrm{L}$ ratio were studied. Both the $\alpha$-TCP and DCPA powders in their system had the median particle sizes of about $5 \mu \mathrm{m}$, while in our system the median size of $\alpha$-TCP was $15.8 \mu \mathrm{m}$ and that of DCPA was $1.4 \mu \mathrm{m}$. The P/L ratio was $3.33 \mathrm{~g} / \mathrm{mL}$ in theirs and $3.0 \mathrm{~g} / \mathrm{mL}$ in our system. The measured $H T$ of $32 \mathrm{~min}$ was almost identical as the $H T$ of $30 \mathrm{~min}$ measured in the present study. Bermudez et al., [20] reported $\mathrm{OCP}$ as the $\mathrm{CPC}$ reaction product whereas $\mathrm{HA}$ 
was formed in our CPC, despite the use of water as the cement liquid in both CPCs. It is noteworthy that Bermudez et al., [20] reported that their cement paste had a relatively high initial $\mathrm{pH}$ of about 9 , which decreased to about $\mathrm{pH} 8$ after $1 \mathrm{~d}$. The higher $\mathrm{pH}$ can be attributed to the smaller $\alpha$-TCP particle size (about 5 $\mu \mathrm{m})$, leading to a more rapid dissolution. It appears that this higher $\mathrm{pH}$ condition was conducive to OCP formation. These findings indicate that even for the same CPC powder mixture of $\alpha$-TCP + DCPA, the major cement product depended strongly on the solid particle size distributions. Further, for a given cement solid mixture, e.g., $\alpha$-TCP + DCPA, OCP can form under widely different cement liquid conditions, e.g., water in Bermudez et al. [20] and $0.5 \mathrm{~mol} / \mathrm{L}$ phosphate solution in the present study. Finally, based on the literature as well data from our preliminary experiments, OCP does not appear to form in any CPC mixture that does not contain $\alpha$-TCP.

The DTS of the OCP-forming CPC reported by Bermudez et al., [20] was about $4.3 \mathrm{MPa}$, which is nearly identical to the $4.4 \mathrm{MPa}$ found for the OCPforming cement produced with the phosphate solution as the liquid in the present study. These values are significantly lower than the $9.1 \mathrm{MPa}$ measured for the HA-forming cement produced with the use of water as the cement liquid. The findings suggest that OCP-forming cements are likely to have much lower DTS than HA-forming cements, regardless of particle sizes of the cement starting materials.

Although OCP can readily form by the spontaneous hydrolysis of $\alpha$-TCP at $\mathrm{pH}$ of about $6.1[33,34]$, our preliminary data indicated that the use $\alpha$-TCP powder alone (without DCPA) with either distilled water or the phosphate solution did not produce a hardening cement. This suggests that the DCPA was a necessary additional cement component, and its role was to compensate for the differences between $\alpha$-TCP and OCP in terms of the acid/base content and $\mathrm{Ca} / \mathrm{P}$ molar ratio. It can be seen from calcium phosphate solubility phase diagrams [35] that DCPA is not more soluble than OCP under neutral and acidic pHs, whereas $\alpha$-TCP is considerably more soluble than OCP at all pHs below 11 [35]. Thus, it can be concluded that $\alpha$-TCP and not DCPA is the likely driving force of OCP formation in the $\alpha$-TCP + DCPA cement.

In the present studies the $\mathrm{CPC}$ reaction products were HA or OCP-like precipitate (OCP + HA), depending, respectively, on whether water or a phosphate solution was used as the cement liquid. In either case the large amounts of $\alpha$-TCP and DCPA remained unreacted; about 55 mass \% with phosphate solution after $7 \mathrm{~d}$ incubation in PLS, and about 50 mass \% with water as the cement liquid after $3 \mathrm{~d}$ incubation in PLS. In CPCs composed of TTCP and DCPA, with particle sizes similar to those of $\alpha$-TCP and DCPA, respectively, used in the present study, HA was the major phase in the product (about 85 mass \%) after $1 \mathrm{~d}$ with only a small amount (15 mass \%) of TTCP left unreacted [23, 25]. TTCP is considerably more soluble than $\alpha$-TCP for $\mathrm{pH}<10$ conditions [35], thus it has a greater driving force than does $\alpha$-TCP for hydrolysis. However, this does not explain why the $\alpha$-TCP + DCPA $\rightarrow$ OCP (or HA) reaction was so slow since only about 45 mass \% or 50 mass $\%$ of the reactants were converted. No XRD data was reported by Bermudez et al. [20], making it difficult to compare the extent of OCP formation in their studies and the present studies. The slow reaction during immersion for up to $7 \mathrm{~d}$ in PLS may explain why the porosity and DTS of the cement were unaffected by the incubation.

In our preliminary studies powder mixtures consisting of the same $\alpha$-TCP and DCPA but with $\mathrm{Ca} / \mathrm{P}$ molar ratios of 1.25 and 1.40 were prepared. These powdered mixtures when mixed with $0.5 \mathrm{~mol} / \mathrm{L}$ phosphate solution at $\mathrm{P} / \mathrm{L}$ of $3.0 \mathrm{~g} / \mathrm{mL}$ hardened in $5.0 \mathrm{~min} \pm 0.5 \mathrm{~min}$ $(\mathrm{n}=6)$ and produced OCP as a product. In other preliminary experiments the $\alpha$-TCP and DCPA powder mixture with the $\mathrm{Ca} / \mathrm{P}$ ratios of 1.33 were mixed with $0.5 \mathrm{~mol} / \mathrm{L}$ phosphate solutions with $\mathrm{pHs}$ of 5.4 or 6.6 at $\mathrm{P} / \mathrm{L}$ of $3 \mathrm{~g} / \mathrm{mL}$, and these pastes also hardened in $5.0 \min \pm 0.5 \min (n=6)$ and produced OCP precipitates. These preliminary findings indicated that fast hardening OCP forming CPCs with a range of $\mathrm{Ca} / \mathrm{P}$ ratios and using cement liquids of different $\mathrm{pHs}$ can be formulated.

A previous study [11] showed that OCP, in aggregate forms, when implanted into the subperiosteal areas of mice were found to lead to new bone formation more rapidly than $\mathrm{HA}$ or $\mathrm{Ca}$-deficient HA. OCP was unique in that fine filaments and granular materials in the newly formed bone matrix were detected around the remnants of OCP particles as short as seven days after implantation. A subsequent study [36] found that when synthetic OCP was implanted into the critical-sized defects in rat calvaria, bone formation was initiated from the margin of the defect and on the implanted OCP away from the margin of the defect. These results support the feasibility of the potential advantages of using bone graft materials that contain OCP as a component. Further in vitro and in vivo studies are warranted to investigate whether OCP forming CPCs may have greater osteoconductivity than CPCs that form HA, carbonated HA, Ca-deficient HA, or brushite as the major phase. 


\section{Conclusions}

The $\alpha$-TCP and DCPA reaction products were HA or OCP + HA, depending, respectively, on whether water or a phosphate solution was used as the cement liquid. In either case $\alpha$-TCP and DCPA remained unreacted in the amount of about 50 mass $\%$ when water and about 55 mass \% when $0.5 \mathrm{~mol} / \mathrm{L}$ phosphate solution was the cement liquid. The presence of phosphate in cement liquid accelerated the cement hardening from $30 \mathrm{~min}$ to 5 min, and induced formation of OCP.

\section{Acknowledgment}

This investigation was supported, in part, by USPHS research Grant R01-DE11789 to the American Dental Association Foundation from the National Institutes of Health-National Institute of Dental and Craniofacial Research and is part of the dental research program conducted by the National Institute of Standards and Technology in cooperation with American Dental Association Foundation.

\section{References}

[1] W. E. Brown, J. P. Smith, J. R. Lehr, and A. W. Frazier, Octacalcium Phosphate and Hydroxyapatite: Crystallographic and Chemical Relations between Octacalcium Phosphate and Hydroxyapatite, Nature 196, 1050-1054 (1962).

[2] M. Mathew, W. E. Brown, L. W. Schroeder, and B. Dickens, Crystal Structure of Octacalcium Bis(Hydrogenphosphate) Tetrakis(Phosphate) Pentahydrate, $\mathrm{Ca}_{8}\left(\mathrm{HPO}_{4}\right)_{2}\left(\mathrm{PO}_{4}\right)_{4} \cdot 5 \mathrm{H}_{2} \mathrm{O}$, J. Chem. Crystallogr. 18, 235-250 (1988).

[3] R. Z. LeGeros, G. Daculsi, I. Orly, T. Abergas, and W. Torres, Solution-mediated Transformation of Octacalcium Phosphate (OCP) to Apatite, Scanning Microsc. 3, 129-138 (1989).

[4] J. L. Meyer and E. D. Eanes, A Thermodynamic Analysis of the Secondary Transition in the Spontaneous Precipitation of Calcium Phosphate, Calcif. Tissue Res. 25, 209-216 (1978).

[5] O. Suzuki, S. Kamakura, T. Katagiri, M. Nakamura, B. Zhao, Y. Honda, and R. Kamijo, Bone Formation Enhanced by Implanted Octacalcium Phosphate Involving Conversion into Ca-deficient Hydroxyapatite, Biomaterials 27, 2671-2681 (2006).

[6] Y. Liu, P. R. Cooper, J. E. Barralet, and R. M. Shelton, Influence of Calcium Phosphate Crystal Assemblies on the Proliferation and Osteogenic Gene Expression of Rat Bone Marrow Stromal Cells, Biomaterials 28, 1393-1403 (2007).

[7] R. M. Shelton, Y. Liu, P. R. Cooper, U. Gbureck, M. J. German, and J. E. Barralet, Bone Marrow Cell Gene Expression and Tissue Construct Assembly using Octacalcium Phosphate Microscaffolds, Biomaterials 27, 2874-2881 (2006).

[8] T. Anada, T. Kumagai, Y. Honda, T. Masuda, R. Kamijo, S. Kamakura, N. Yoshihara, T. Koriyagama, H. Shimauchi, and O. Suzuki, Dose-Dependent Osteogenic Effect of Octacalcium Phosphate on Mouse Bone Marrow Stromal Cells, Tissue Eng. Part A 14, 965-978 (2008).
[9] S. Ban, T. Jinde, and J. Hasegawa, Phase Transformation of Octacalcium Phosphate in vivo and in vitro, Dent. Mater. J. 11, 130-140 (1992).

[10] O. Suzuki, M. Nakamura, Y. Miyasaka, M. Kagayama, and M. Sakurai, Maclura Pomifera Agglutinin-Binding Glycoconjugates on Converted Apatite from Synthetic Octacalcium Phosphate Implanted into Subperiosteal Region of Mouse Calvaria, Bone Miner. 20, 151166 (1993).

[11] O. Suzuki, M. Nakamura, Y. Miyasaka, M. Kagayama, and M. Sakurai, Bone Formation on Synthetic Precursors of Hydroxyapatite, Tohoku J. Exp. Med. 164, 37-50 (1991).

[12] F. Sugihara, H. Onishi, S. Kushitani, N. Iwaki, K. Mandai, K. Minamigawa, E. Tshuji, M. Yoshikawa, and T. Toda, Bone Tissue Reaction of Octacalcium Phosphate, in Bioceramics, Vol. 8, J. Wilson, L. L. Hench, and D. Greenspan, eds., Pergamon Press, Oxford, England (1995) 89-91.

[13] S. Kamakura, Y. Sasano, H. Homma-Ohki, M. Nakamura, O. Suzuki, M. Kagayama, and M. Katsutoshi, Multinucleated Giant Cells Recruited by Implantation of Octacalcium Phosphate (OCP) in Rat Bone Marrow Share Ultrastructural Characteristics with Osteoclasts, J. Electron Microsc. (Tokyo) 46, 397-403 (1997).

[14] F. Barrere, C. M. van der Valk, R. A. J. Dalmeijer, G. Meijer, C. A. van Blitterswijk, K. de Groot, and P. Layrolle, Osteogenecity of Octacalcium Phosphate Coatings Applied on Porous Metal Implants, J. Biomed. Mater. Res. Part A 66, 779788 (2003).

[15] H. Imaizumi, M. Sakurai, O. Kashimoto, T. Kikawa, and O. Suzuki, Comparative Study on Osteoconductivity by Synthetic Octacalcium Phosphate and Sintered Hydroxyapatite in Rabbit Bone Marrow, Calcif. Tissue Int. 78, 45-54 (2006).

[16] F. Barrere, P. Layrolle, C. A. van Blitterswijk, and K. de Groot, Biomimetic Calcium Phosphate Coatings on Ti6Al4V: A Crystal Growth Study of Octacalcium Phosphate and Inhibition by $\mathrm{Mg}^{2+}$ and $\mathrm{HCO}_{3}^{-}$, Bone 25, 107S-111S (1999).

[17] A. Bigi, B. Bracci, F. Cuisinier, R. Elkaim, M. Fini, I. Mayer, I. N. Mihailescu, G. Socol, L. Sturba, and P. Torricelli, Human Osteoblast Response to Pulsed Laser Deposited Calcium Phosphate Coatings, Biomaterials 26, 2381-2389 (2005).

[18] P. Habibovic, C. M. van der Valk, C. A. van Blitterswijk, K. de Groot, and G. Meijer, Influence of Octacalcium Phosphate Coating on Osteoinductive Properties of Biomaterials, J. Mater. Sci. Mater. Med. 15, 373-380 (2004).

[19] H. Monma, A. Makishima, M. Mitomo, and T. Ikegami, Hydraulic Properties of the Tricalcium Phosphate-Dicalcium Phosphate Mixture, Nippon Seramikkusu Kyokai Gakujutsu Ronbunshi (J. Ceram. Soc. Jpn.) 96, 878-880 (1988).

[20] O. Bermudez, M. G. Boltong, F. L. M. Driessens, and J. A. Planell, Development of an Octacalcium Phosphate Cement, J. Mater. Sci. Mater. Med. 5, 144-146 (1994).

[21] M. Sena, Y. Yamashita, Y. Nakano, M. Ohgaki, S. Nakamura, K. Yamashita, and Y. Takagi, Octacalcium Phosphate-based Cement as a Pulp-capping Agent in Rats, Oral Surg. Oral Med. Oral Pathol. Oral Radiol. Endod. 97, 749-755 (2004).

[22] L. C. Chow, M. Markovic, S. Takagi, and M. Cherng, Effect of Cement Liquid on the Physical Properties of the Cement, Innov. Techn. Biol. Med. 18 (Numero Special GRIBOL 97), 11-14 (1997).

[23] L. C. Chow, M. Markovic, and S. Takagi, Calcium Phosphate Cements, in Cements Research Progress, Chapter 7, L. J. Struble, ed., American Ceramic Society, Westerville, Ohio (1998) 215-238 
[24] L. C. Chow, M. Markovic, and S. Takagi, Formation of Hydroxyapatite in Cement Systems: Effects of Phosphate, Phosphorus, Sulfur and Silicon and the Related Elements 146, 129-132 (1999).

[25] S. Hirayama, S. Takagi, M. Markovic, and L. C. Chow, Properties of Calcium Phosphate Cements with Different Tetracalcium Phosphate and Dicalcium Phosphate Anhydrous Molar Ratios, J. Res. Natl. Inst. Stand. Technol. 113, 311-320 (2008).

[26] S. Frukhtbeyn, M. Markovic, L. Chow, and S. Takagi, Factors Influencing Hydrolysis of Dicalcium Phosphate Anhydrous, J. Dent. Res. 82 (Special Issue), Abst. No. 3585 (2004).

[27] L. C. Chow, M. Markovic, S. A. Frukhtbeyn, and S. Takagi, Hydrolysis of Tetracalcium Phosphate under a near Constantcomposition Condition-Effects of $\mathrm{pH}$ and Particle Size, Biomaterials 26, 393-401 (2005).

[28] L. C. Chow, S. Hirayama, S. Takagi, and E. Parry, Diametral Tensile Strength and Compressive Strength of a Calcium Phosphate Cement: Effect of Applied Pressure, J. Biomed. Mater. Res. Part B (Appl. Biomater.) 53, 511-517 (2000).

[29] N. Eidelman, L. C. Chow, and W. E. Brown, Calcium Phosphate Saturation Levels in Ultrafiltered Serum, Calcif. Tissue Int. 40, 71-78 (1987).

[30] J. R. Lehr, E. H. Brown, A. W. Frazier, J. P. Smith, and R. D. Thrasher, Crystallographic Properties of Fertilizer Compounds, Chemical Engineering Bulletin No. 6, Tennessee Valley Authority, Muscle Shoals, Alabama (1967) p. 9.

[31] K. Ishikawa, S. Takagi, L. C. Chow, and K. Suzuki, Reaction of Calcium Phosphate Cements with Different Amounts of Tetracalcium Phosphate and Dicalcium Phosphate Anhydrous, J. Biomed. Mater. Res. 46, 504-510 (1999).

[32] L. C. Chow, S. Takagi, and K. Ishikawa, Formation of Hydroxyapatite in Cement Systems, in Hydroxyapatite and Related Materials, P. W. Brown and B. Constantz, eds., CRC Press, Boca Raton (1994) 127-137.

[33] H. Monma, Preparation of Octacalcium Phosphate by the Hydrolysis of $\alpha$-Tricalcium Phosphate, J. Mater. Sci. 15, 24282434 (1980).

[34] M. Markovic, B. O. Fowler, and W. E. Brown, Octacalcium Phosphate Carboxylates. 1. Preparation and Identification, Chem. Mater. 5, 1401-1405 (1993).

[35] L. C. Chow, Solubility of Calcium Phosphates, in Octacalcium Phosphate, L. C. Chow and E. D. Eanes, eds., Monographs Oral. Sci., Vol. 18, Karger, Basel (2001) 94-111.

[36] S. Kamakura, Y. Sasano, H. Homma, O. Suzuki, M. Kagayama, and K. Motegi, Implantation of Octacalcium Phosphate Nucleates Isolated Bone Formation in Rat Skull Defects, Oral. Diseases 7, 259-265 (2001).

About the authors: Dr. Milenko Markovic and Dr. Laurence C. Chow are physical chemists in the Dental Chemistry Division of the Paffenbarger Research Center, American Dental Association Foundation at Polymer Division, the National Institute of Standards and Technology (NIST) Materials Science and Engineering Laboratory. NIST is an agency of the U.S. Department of Commerce. 